\title{
Consumers attraction to the crowdfunding of innovative products in digital era
}

\author{
O. Firsanova \\ Marketing Department \\ St. Petersburg State University of \\ Economics \\ St. Petersburg, Russia \\ o.firsanova@mail.ru
}

\author{
V. Baykov \\ Marketing Department \\ St. Petersburg State University of \\ Economics \\ St. Petersburg, Russia \\ siemours@gmail.com
}

\begin{abstract}
The promotion of innovative products in the Internet requires the constant updating of content, which eventually loses its relevance. For the modern BtC market, crowdfunding, as a model of searching for a project investments based on non-financial rewards for consumers, becomes more and more popular. On crowdfunding, the content plays the role of a marketing tool, which forms consumer's interest in an innovative product, and generally attracting them to the project. The effectiveness of content depends on the rate of its obsolescence and is associated with the rate of consumers attraction. This article assesses the rate of content obsolescence on Internet-sites similar to crowdfunding, as well as the rate at which consumers are attracted to Russian crowdfunding platforms on the basis of data from 200 campaigns.
\end{abstract}

Keywords-innovative marketing, innovative products, crowdfunding, rate of consumers attraction, rate of content's obsolescence

\section{INTRODUCTION}

Any marketing activity to promote innovative products in the Internet can't do without releasing relevant content. The content loses its relevance over time, which forces firms to update it. For some companies, new content is the main "commodity" - media, information sites, blogs, etc. For others it is a way to inform consumers about product development, its capabilities, updates, etc. In any case, it is important to determine the effectiveness of new content for both first and second companies.

The effectiveness of content should be considered from the consumer's behavior point of view, linking it with stages of purchase decision-making process. In other words, the effectiveness of content can be estimated both for consumers who make purchases, and for those who just learned about a new product category.

To determine the effectiveness of the content the way the company interacts with consumers has the most significant importance. In particular, for BtB markets, where long-term mutually beneficial relations are built between the companies, where the purchase is mostly determined by production technologies, material features, wholesale lot size, etc. the use of industry journals is important. For BtC market, where the number of consumers in comparison with the BtB market is huge, and the process of making a purchase is shorter by many times, it is necessary to use such interconnection channels that are very efficient and accessible, such as the Internet. For innovative products, $\mathrm{BtC}$ market companies are increasingly using crowdfunding as a channel for interaction with consumers.

Crowdfunding is a model of searching for a project investments based on non-financial reward. For their investments, consumers or "sponsors" receive awards in the form of the product itself, additional bonuses to it, meetings with representatives of the company or "eminent" developers, taking part in the very process of creating an innovative product, etc.

The effectiveness of this source of financing innovative products can be judged by the high growth rates of the amount of funds raised by them. As many experts note, the amounts of investments raised with the help of crowdfunding are doubled every year (Figure 1) [6].

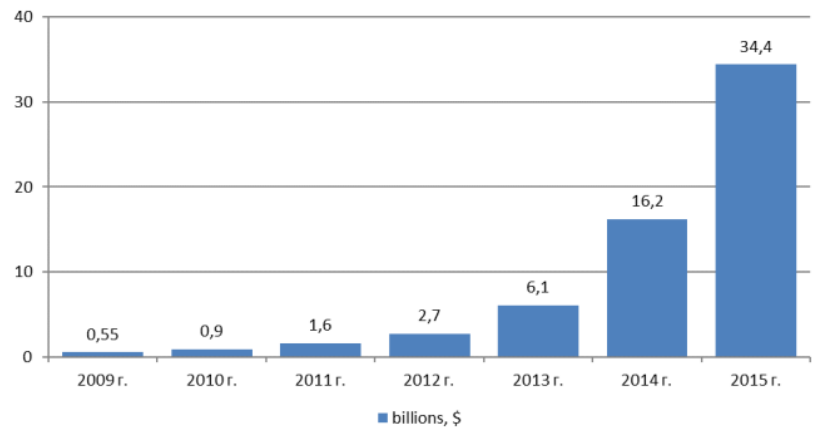

Fig. 1. The amount of funds raised by firms for the production of innovative products and services with the help of crowdfunding in 20092015 , in billions of dollars [6]

As follows from figure 1 if in 2009 the amount of funds raised by crowdfunding was slightly more than 500 million dollars, by the end of 2015 this amount was already 34,4 billion dollars.

By the end of 2012, there were more than 460 "crowdfunding platforms" operating around the world, and by 2016 their number had increased to almost 2000. According to some experts by 2020 crowdfunding will be able to raise more funds than venture capital [1] (Figure 2). 


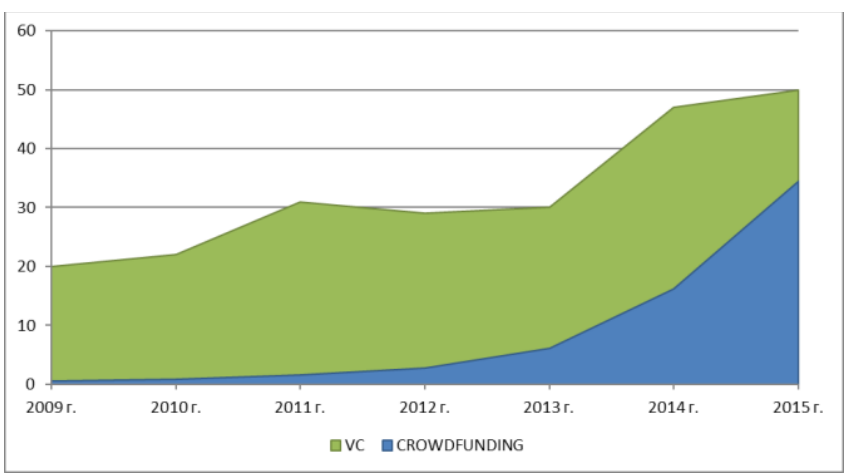

Fig. 2. The amount of investment raised by crowdfunding in comparison with venture capital (VC) for 2009-2015, in billions of dollars [1]

In Russia crowdfunding is also developing quite actively. In particular, 9082 projects with a total amount of raised funds exceeding 643 million rubles were presented at Russian "sites" with the participation of 160,000 "sponsors" [8, date of reference: 14.04.2018].

It is also worth noting that there is a growing confidence in crowdfunding projects among consumers. This can be seen from how often the latter invest in various campaigns at the very beginning of their existence. On average, the whole process of financing takes 30 days, and, as practice shows, it is more often that the largest amount of funds comes from new consumers during the first days (Figure 3), after which the rate of their growth is equalized.

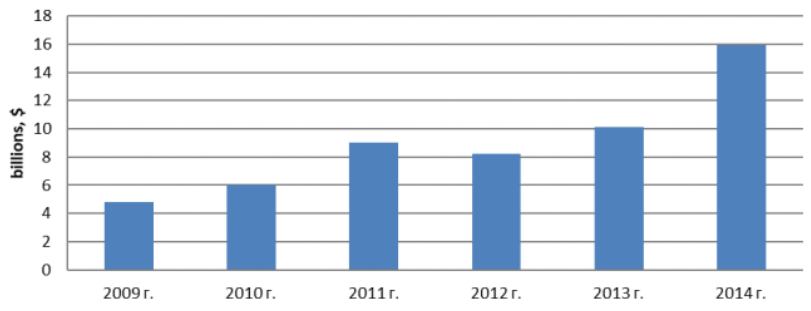

Fig. 3. The amount of funds raised by the project of crowdfunding during the first days [3]

\section{MAIN PART}

Returning to the question of assessing the effectiveness of the new content in crowdfunding projects, it should be noted that it will mostly depend on the rate at which new consumers are attracted.

In order to be interested in buying an innovative product on crowdfunding platforms, the consumer must have certain knowledge, which is replenished by new content.

In crowdfunding projects, consumers who are interested in an innovative product, pre-pay it. In this case, there are various payment options, for example, a symbolic amount of $1 \$$, the price of the product itself with a guarantee of its receipt on the specified date, as well as various options that "add" bonuses to the product. After payment, consumer's funds are transferred to the project's account.

Information about the properties of innovative product, its possible modifications, improvements in the process of collecting exceeding amounts of money, etc. allows consumers to quickly form the perceived value of the product. On the basis of all available information, they decide whether to pay, reduce or increase the amount of money already paid, etc. Therefore, it is important for companies to determine how often it is necessary to release new content on the crowdfunding platforms [2].

It should be noted that the activities of companies to promote innovative products with the use of crowdfunding are objectively connected with restrictions. Despite the growing popularity of crowdfunding sites, the development of Internet technologies, methods of products delivery, etc., the number of users on those sites is less than that of Internet users in general. In other words, the attraction of new consumers to the crowdfunding of an innovative product has a certain limit, which can be taken into account when applying the logistic Verhulst equation adapted for innovation marketing (Eq. 1) to evaluate the effectiveness of new content [7].

$$
P(t)=\frac{P_{0} K e^{r t}}{K-P_{0}+P_{0} e^{r t}}
$$

with: P - number of consumers; P0 - the initial number of consumers; $\mathrm{K}$ - the capacity of the niche or all users of a specific crowdfunding platform; $r$ - rate of consumers attraction; $\mathrm{t}$ - time.

To assess the content effectiveness, the most important variable is the " $\mathrm{r}$ " or the rate of consumers attraction. This variable is considered to be a constant, i.e. throughout the crowdfunding of an innovative product the number of consumers every day grows at the same rate. This implies that the behavior of consumers is not affected by the release of new information about the product, demonstration of its capabilities, advertising on other Internet resources, etc.

This statement can't be accepted as true, as companies promoting innovative products on crowdfunding sites actively use marketing tools, influencing the behavior of consumers, speeding up their decision-making process. Therefore, " $r$ " can't be a constant, its value mostly depends on the relevance of the content or, in other words, the rate of its obsolescence.

To determine the rate of content's obsolescence on crowdfunding sites, its closest analogues on other Internet resources can be considered, for example, on several YouTube channels. The data on consumers attraction towards implementation of two targeted actions were analyzed viewing the video and subscribing to the channel. The most important is the subscription to the channel, since it shows the number of unique users interested in the content of a particular channel. For crowdfunding, such target action may be the order of a product, participation in its testing, etc. The only difference is that one can become the "subscriber" of crowdfunding project only after paying for one of its options. However, since many sites have an option with a price of $1 \$$, almost anyone can make a targeted action, similar to the users of YouTube (Figure 4). 


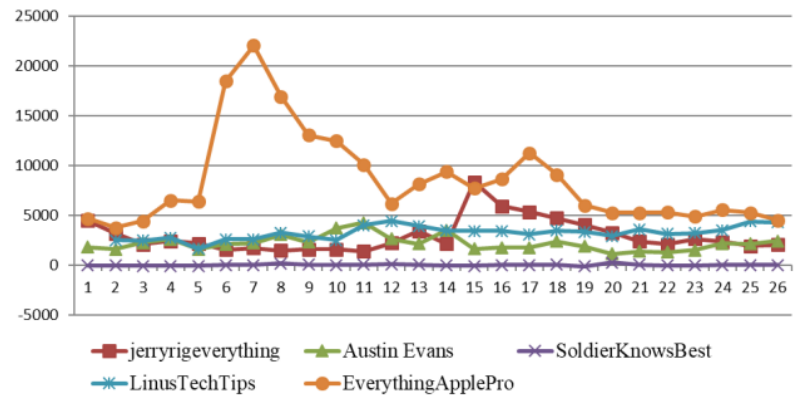

Fig. 4. Number of subscriptions on the channels when new content is released

As follows from Figure 4, on average, the content remains relevant for 3 days. At the same time, on the second day $20 \%$ fewer subscribers are attracted to the channel compared with day one, and on the third day $44 \%$ fewer than in day one. In order to determine the average rate of content's obsolescence, equation (2) can be used [5].

$$
\begin{aligned}
& r(t)=\frac{\left(\frac{\Delta P}{\Delta t}\right)}{P_{t-1}} ; \text { with } \Delta t=1 \\
& r(t)=\frac{\Delta P}{P_{t-1}}=\frac{P_{t}-P_{t-1}}{P_{t-1}}
\end{aligned}
$$

with: P - the number of consumers who have committed the targeted action; $\mathrm{t}$ - the day.

The calculation of the rate of content's obsolescence according to the equation (2) is presented in Table 1.

\begin{tabular}{|c|c|c|c|c|c|c|}
\hline & & \multicolumn{5}{|c|}{ The rate of content's obsolescence } \\
\hline & & \multicolumn{5}{|c|}{ Day } \\
\hline & & 1 & 2 & 3 & 4 & 5 \\
\hline \multirow{7}{*}{ 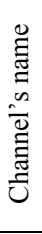 } & \multirow{2}{*}{ EverythingApplePro } & $-0,23$ & $-0,18$ & $-0,03$ & $-0,11$ & $-0,18$ \\
\hline & & $-0,19$ & $-0,28$ & $-0,07$ & 0,00 & 0,01 \\
\hline & jerryrigeverything & $-0,29$ & $-0,07$ & $-0,08$ & $-0,08$ & $-0,10$ \\
\hline & LinusTechTips & $-0,11$ & $-0,11$ & $-0,01$ & 0,00 & $-0,07$ \\
\hline & Unbox Therapy & $-0,13$ & $-0,26$ & $-0,22$ & 0,00 & $-0,03$ \\
\hline & Austin Evans & $-0,38$ & $-0,12$ & 0,23 & $-0,27$ & 0,03 \\
\hline & SoldierKnowsBest & $-0,56$ & $-0,24$ & 0,16 & 0,32 & $-0,13$ \\
\hline & Average value & $-0,27$ & $-0,18$ & 0,00 & $-0,02$ & $-0,07$ \\
\hline \multicolumn{7}{|c|}{ Average rate per day } \\
\hline & & & & & & \\
\hline
\end{tabular}

TABLE I. THE RATE OF CONTENT'S OBSOLESCENCE FROM THE DAY IT WAS RELEASED TO THE APPEARANCE OF A NEW ONE

No matter how high the value of the number of consumers attracted to the crowdfunding project is (section A of Figure 5 ), sooner or later it will start to fall steadily (section B of Figure 5).

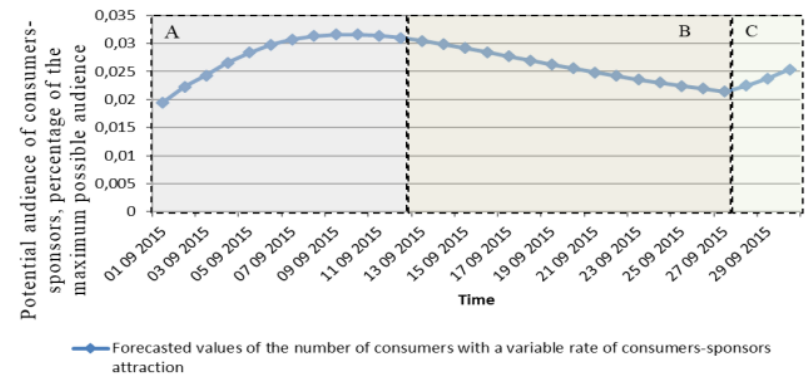

Fig. 5. Changes in numbers of attracted consumers taking into account the content's obsolescence

A slight increase in the rate of consumers attraction, observed in sector $\mathrm{C}$, is usually caused by the "success" factor of the campaign (consumers invest their money in a project, the risk of non-completion of which is minimal).

It should be noted that for companies to plan marketing activities on the crowdfunding platforms it isn't enough only to know the rate of content's obsolescence. It is necessary to understand the «dimension» of the rate of attracting consumers per day.
For this purpose, on the on-line resource "thestartman.ru" data on 100 "successful" and 100 "unsuccessful" crowdfunding campaigns were collected. Successful were those campaigns, which in the allotted time collected, at least, the required amount of money. If the company did not succeed, it was categorized as unsuccessful. Table 2 presents an example of calculating the rate of consumers, using equation (2), attraction by the amount of funds raised and by the number of consumers involved.

TABLE II. AN EXAMPLE OF CALCULATING THE RATE OF CONSUMERS ATTRACTION (R) ON THE CROWDFUNDING PLATFORM BASED ON THE PROJECT DATA - «SPACE SATELLITE «MAYAK»» [8]

\begin{tabular}{|l|l|l|l|l|}
\hline Day & $\begin{array}{c}\text { Number of } \\
\text { funds } \\
\text { raised }\end{array}$ & $\begin{array}{c}\text { Number of } \\
\text { consumers } \\
\text { attracted }\end{array}$ & $\begin{array}{c}\text { r, calculated } \\
\text { on the basis } \\
\text { of funds } \\
\text { raised }\end{array}$ & $\begin{array}{l}\mathbf{r}, \text { calculated } \\
\text { on the basis of } \\
\text { the number of } \\
\text { sponsors }\end{array}$ \\
\hline 1 & 25900 & 35 & - & - \\
\hline 2 & 75074 & 102 & 1,90 & 1,90 \\
\hline 3 & 101874 & 139 & 0,36 & 0,36 \\
\hline 4 & 186624 & 254 & 0,83 & 0,83 \\
\hline 5 & 208424 & 284 & 0,12 & 0,12 \\
\hline$\ldots$ & $\ldots$ & $\ldots$ & $\ldots$ & $\ldots$ \\
\hline 37 & 1951644 & 2655 & 0,01 & 0,01 \\
\hline 38 & 1985244 & 2700 & 0,02 & 0,02 \\
\hline 39 & 1994546 & 2713 & 0,00 & 0,00 \\
\hline
\end{tabular}


Carrying out similar calculations for 200 crowdfunding campaigns, it was possible to calculate the average values of the rates of consumers attraction for "successful" and "unsuccessful" projects. On average, for all "unsuccessful" campaigns on crowdfunding sites, the rate of consumers attraction is $r=0,23$.

\section{CONCLUSION}

Using the Verhulst equation (1), we can clearly show at what point in time the information begins to lose its relevance. At the same time, knowing the values of the variable " $r$ " and how it changes with time (by $10-11 \%$ each day), the producer can plan the release of new content even before the former one starts to lose its relevance. As a result, the company can reduce costs. For example, if content without any updates is capable to attract new consumers for thirteen days, as shown at sector A of Figure 5, new information should be released only when this effect goes to a decline (sector B). As a result, the company needs to periodically update the information, thus causing an abrupt change in the variable " $r$ " (it returns to a certain level), thereby increasing the number of attracted consumers by the time the crowdfunding of the innovative product ends.

\section{REFERENCES}

[1] Barnett Ch. Trends Show Crowdfunding To Surpass VC In 2016 Available http://www.forbes.com/sites/Chancebarnett/2015/06/09/trends-showcrowdfunding-to-surpass vs-in-2016/\#7e0e1d994547.

[2] Baykov V. G. Rationale for the use of crowdfunding as a tool for development and promotion of a new product in the sphere of marketing. // Science review N7, 2017 - p. $101-109$.
[3] Haahr J. K., Lee R. E. Jr.: 2015 PENSCO crowdfunding report. PENSCO Insights

[4] Jon K. Haahr, Robert E. Lee, Jon K. Haahr Jr.: 2015 PENSCO crowdfunding report / PENSCO Insights, p.32

[5] Kolesnikov S.I. Ecology. Study Guide. // Publishing and trading corporation "Dashkov and Co", Science Press, Moscow. - 2007 - p. 116.

[6] Massolution - 2015CF. The crowdfunding industry report, 2016. Available at: $\quad$ reports.crowdsourcing.org/index. php?route=product\&product_icp54.

[7] Riznichenko G. U. Lectures on mathematical models in biology. - 2nd ed. corrected and supplemented. - M.- Izhevsk: Institute for Computer Research, SRC "Regular and chaotic dynamics ", 2010. - 560 p.

[8] Startman.ru. "Space satellite «Mayak», Feb. 1, 2016, Retrieved from: thestartman.ru/project/4913

[9] G. Bagiev, O. Pogrebova, E. Konnikov. "Marketing platform of organization of system-spatial complex "PSE" (Production - Science Education)". [Proceedings of the 2017 International Conference "Quality Management, Transport and Information Security, Information Technologies", pages 466-470, 2017].

[10]O. Yuldasheva, E. Khalina, O. Pogrebova, J. Solovjova, "Values of Sustainable Development in Consumer Behavior: Case of Russia." Espacios, vol. 38 (54), 2017.

[11]Nikolova, L. V., Kuporov, J. J., \& Rodionov, D. G. (2015). Risk management of innovation projects in the context of globalization. International Journal of Economics and Financial Issues, 5 (3S), p. 6872

[12]Glukhov, V.V., Balashova, E. (2015). Operations strategies in infocommunication companies. Lecture Notes in Computer Science (including subseries Lecture Notes in Artificial Intelligence and Lecture Notes in Bioinformatics), 9247, pp. 554-558. DOI: 10.1007/978-3-31923126-6_48.

[13] Klochkov, Y., Odinokov, S., Klochkova, E., Ostapenko, M., Volgina, A. (2016). Development of certification model. 2016 5th International Conference on Reliability, Infocom Technologies and Optimization, ICRITO 2016: Trends and Future Directions,7784937, pp. 120-122. DOI: 10.1109/ICRITO.2016.778493 